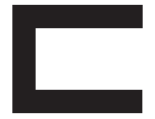

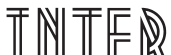

ERCE

CIENTÍFICAS

EXATAS E TECNOLÓGICAS

ISSN IMPRESSO - 2359-4934

E-ISSN - 2359-4942

DOI - 10.17564/2359-4934.2016v2n2p19-26

\title{
ANÁLISE GERAL DOS PROCESSOS DE FABRICAÇÃO DE MATERIAIS CERÂMICOS PARA O SETOR DA CONSTRUCÇÃO CIVIL
}

Andrea Quaranta Barbosa ${ }^{1}$

Diego Melo Costa ${ }^{3}$
Cesar Douglas Bezerra dos Santos

tivo deste trabalho é fazer uma análise das etapas de exploração, extração e tratamento da argila, bem como moldagem, secagem e cozimento, visando à produção de materiais cerâmicos de boa qualidade para que sejam utilizados em diversos segmentos da construção civil.

\section{PALAVRAS-CHAVE}

Construção Civil. Argila. Cerâmica. Fabricação. 


\section{RESUMEN}

Los materiales cerámicos fueron los primeros materiales utilizados por los seres humanos para crear utensilios y herramientas rudimentarias de fabricación. En ese momento, las etapas de fabricación no estaban bien definidas y no había controle en las diversas etapas de producción, lo que resulta en la obtención de un material de baja calidad. Por lo tanto, con el fin de producir buenos materiales utilizando la arcilla como materia prima, se percibió a través de los estudios que se necesitan etapas predeterminadas a seguir y observar. Por lo tanto, el objetivo de este estudio fue analizar las etapas de exploración, extracción y procesamiento de la arcilla, así como el moldeo, secado y cocción, con el objetivo de la producción de materiales cerámicos de buena calidad para utilizar en diversos sectores de la construcción.

\section{PALABRAS CLAVE}

Construcción, Arcilla, Cerámica, Manufactura.

\section{ABSTRACT}

Ceramic materials were the first materials to be used by humans to create tools and manufacturing rudimentary tools. At that time, the manufacturing steps were not well defined and controls did not show the various production steps, resulting in obtaining low quality materials. Thus, in order to produce good materials using clay as raw material, it was observed through studies and trials predetermined steps are needed to be followed and observed. Therefore, the aim of this study was to analyze the stages of explora-

tion, extraction and processing of clay and molding, drying and firing, aiming the production of ceramic materials of good quality to be used in various segments of the construction.

\section{KEYWORDS}

Construction. Clay. Ceramic. Manufacture. 


\section{INTRODUÇ̄̃̃O}

Os materiais cerâmicos foram um dos primeiros materiais a serem utilizados pelo homem para a criação de utensílios, como também para a elaboração de ferramentas rudimentares. De acordo com Oliveira (2015),os materiais cerâmicos têm esse nome derivado da palavra grega "Keramus", que significa barro queimado ou argila queimada, onde recentemente, segundo a autora, esse termo ficou mais abrangente e se refere agora, a todo material inorgânico não metálico obtido após tratamento térmico a altas temperaturas.

Segundo Ambrozewicz (2012) para que se produza esse tipo de material, a argila necessita passar por alguns processos de fabricação, tais como, a moldagem, secagem e cozimento, para formar assim um tipo de pedra artificial, que terá diversas finalidades a depender das etapas realizadas durante o processo.

A Associação Brasileira de Cerâmica (ABC), mostra que houve uma rápida evolução por parte das indústrias de cerâmicas brasileiras para produzir materiais de excelente qualidade, tanto para comercialização interna, como também para exportação, devido à facilidade de obtenção de matérias-primas naturais, disponibilidade de tecnologias práticas embutidas nos equipamentos industriais e fontes alternativas de energia. De acordo com a associação, as regiões que mais se desenvolveram no país foram a Sul e Sudeste devido a fatores econômicos e sociais favoráveis, sendo conveniente salientar que a região Nordeste tem apresentado um grau de desenvolvimento considerável, onde a demanda de materiais cerâmicos tem aumentado, principalmente nos segmentos relacionados a construção civil.

O Brasil é um dos maiores produtores e consumidores de cerâmica argilosa do mundo, segundo a Associação Nacional da Indústria Cerâmica o setor está presente em mais de $90 \%$ das obras brasileiras, e representa cerca de $4,8 \%$ da indústria da constru- ção civil, gerando mais de 400 mil postos de trabalhos diretos e 1,25 milhão indiretos. Onde, conforme o Instituto Brasileiro de Geografia e Estatística (IBGE)/Governo federal o setor é constituído por 6.903 empresas, com faturamento anual superior a $\mathrm{R} \$ 18$ bilhões (ANICER, 2014).

0 presente artigo apresenta de forma clara e direta, no formato de revisão bibliográfica, os processos de fabricação dos materiais cerâmicos, com foco na nas etapas de exploração, extração e tratamento da argila, moldagem, secagem e cozimento.

\section{METODOLOGIA}

O caminho inicial percorrido no presente artigo é a elaboração do referencial teórico por meio de uma pesquisa bibliográfica, no qual se realizou uma análise dos processos de fabricação dos materiais cerâmicos no geral, para garantir uma compreensão mais ampla das diversas etapas na produção de diversos tipos de materiais para o setor da construção civil.

Mediante esta pesquisa, será possível observar como ocorre a fabricação e quais os cuidados que se deverá ter ao fabricá-los, pois a depender do material, processos distintos terão que ser aplicados, além dos que estão sendo apresentados.

\section{PROCESSOS DE FABRICAÇÃO DOS MATERIAIS CERÂMICOS}

As argilas são encontradas em depósitos naturais no qual usualmente são chamadas de jazidas (locais onde ocorre a extração), normalmente apresenta características químicas e físicas diferentes, pois para cada depósito há uma situação particular geológica, 
no qual afeta a sua característica, chegando a ser raras em decorrência das suas propriedades tecnológicas valiosas, podendo ou não se assemelhar com as outras argilas encontradas na mesma jazida ou em jazidas distintas (COELHO ET AL., 2007).

Com isso, visando a produção de bons materiais que utilizam argila como matéria-prima, são necessárias fases pré-determinadas, as quais devem ser seguidas, e observadas para que se obtenha materiais de boa qualidade, tanto física como estética (BRITO ET AL., 2015).

Segundo o Mineropar (2007), a água e a energia são dois recursos bastante utilizados durante os processos de fabricação dos produtos cerâmicos, onde o primeiro está presente em quase todas as etapas e o segundo tem o uso centrado principalmente nos processos de secagem e queima, sendo o gás natural e o gás liquefeito do petróleo (GLP), empregados na maioria das empresas. A energia elétrica por sua vez conforme o guia, é empregada nas instalações e maquinários usados para a moagem, mistura das matérias-primas e para a conformação das peças, sendo consumida em quantidade bastante inferior àquela dos combustíveis.

\subsection{EXPLORAÇÃO DE JAZIDA}

No primeiro momento é realizada uma análise dos aspectos gerais da jazida. Nesta etapa são desenvolvidos estudos para observar qual o tipo de argila que será extraída, dessa forma serão analisados os seguintes itens: a qualidade da argila; a análise do volume total disponível; se é possível o acesso para os veículos pesados no local da extração; a logística de distribuição ao consumidor (etapa de extrema importância, pois quanto mais distante for a extração do local da comercialização, maior poderá ser o repasse do valor para o produto) e por fim é analisada a necessidade de se fazer um relatório de impacto no meio ambiente (AMBROZEWICZ, 2012).
Na avaliação das jazidas, deve-se realizar a investigação geotécnica da subsuperfície, retirada de amostras para a realização dos ensaios preliminares, além do planejamento da lavra e exploração. A retirada de argila da jazida tem como pontos importantes: a não-utilização de explosivos, ausência de beneficiamentos que gerem subprodutos tóxicos e a realização fora de corpos hídricos e a céu aberto, mas exige alguns cuidados operacionais: eliminação de riscos de desabamento, interdição de áreas com deslizamentos de massas de terra, criação de acessos seguros e manutenção da estabilidade dos taludes (SILVA ET AL., 2009).

Além desses cuidados, a execução de um projeto de exploração de uma jazida deve apresentar um projeto de recuperação ambiental, sendo que este apresenta custo elevado, contribuindo significativamente no orçamento total da exploração (MECHI; SANCHES, 2010).

\subsection{EXTRAÇ̃̃O DE MATÉRIA-PRIMA}

A primeira coisa a se observar na extração da argila é a retirada de materiais que não terão utilidade e em seguida a questão do escoamento das águas (SILVA, 1991). Pois enfatiza Paschoal e Cunha (2012) que, esse tipo de atividade é capaz de alterar consideravelmente as características naturais do ambiente. Por isso, nesta etapa é necessária a análise eficiente da quantitativa de matéria-prima que a jazida dispõe para extração, pois se caso for feito de maneira despreocupada, sem avaliar as consequências para o local da extração, poderá ocasionar, por meio da extração (explotação), problemas ambientais.

Dentre os tipos de problemas ambientais que esse tipo de atividade pode causar, Paschoal e Cunha (2012) fazem menção do assoreamento nos cursos dos canais fluviais e da alteração na qualidade e na turbidez das águas superficiais, onde propicia o rebaixamento no nível do lençol freático devido às grandes cavas que podem atingir níveis de exploração situados abaixo do afloramento do lençol freático, fazendo 
com que haja o afloramento desta água e consequentemente maior evaporação e redução na vazão dos corpos hídricos superficiais, entre outros.

A extração da matéria-prima pode ser feita com a utilização de equipamentos mais rudimentares, como por exemplo, pás, picaretas e carros de mão, até os mais modernos e mecanizados, como tratores, escavadeiras, entre outros equipamentos (SILVA, 1991).

\subsection{TRATAMENTO DA MATÉRIIA-PRIMA}

Extraída, a argila precisa ser preparada para a industrialização, na própria jazida pode ser feita a separação em lotes de mesma qualidade (composição, dureza, plasticidade etc.). Entre os tratamentos anteriores à fabricação dos produtos cerâmicos destacados por Silva (1991), podemos citar a depuração, trituração, homogeneização e umidificação.

A depuração é um processo no qual ocorre a eliminação de impurezas que possam prejudicar a qualidade final do produto, tais como, raízes mortas, grãos duros, pequenos nós de cal e sais solúveis, por meio de processos particulares, como, por exemplo, a levigação, a sedimentação, a centrifugação, a flotação, a aeração,dentre outros (AMBROZEWICZ, 2012).

A umidificação é processo no qual se faz a mistura de uma quantidade de água precisa para facilitar a homogeneização, deixando a argila mais maleável.

A homogeneização é onde ocorre a mistura da argila com o desengordurante. Esse desengordurante atua como redutor da retração e da plasticidade, ou é adicionado certa quantidade de água para aumentar a plasticidade do material, facilitando assim a moldagem (SILVA ET AL., 2013).

A trituração (maceração) é necessária para melhorar a homogeneização, onde, por meio dela, se obtêm partículas menores, grãos mais finos. Muitas vezes é feita por processos antigos, porém os equipamentos mais comuns utilizados são os moinhos de mandíbula e o de gaiola (MINEROPAR, 2007).

Nesse processo de tratamento como cita Bauer (2011), pode se realizar o que ele chama de apodrecimento da argila, onde a argila é separada e levada para locais ao ar livre, revolvida sumariamente, passando assim por um período de descanso, para que ocorra a fermentação das partículas orgânicas (aumentando assim a plasticidade) e algumas correções com relação ao efeito das pressões sobre a argila. Sendo que certas porcelanas sofrem apodrecimento de até vários anos.

O tratamento da argila (ou simplesmente argila modificada) é comum em muitas áreas de comercialização industrial. Ummartyotina e colaboradores (2016) mostram a importância da etapa do tratamento da matéria-prima, eles citam os excelentes resultados demonstrados pela argila quanto à elevada resistência térmica e química, bem como uma elevada porosidade.

\subsection{MOLDAGEM}

De acordo com Ambrozewicz (2012) essa é a etapa onde se dá a forma definitiva à pasta. Sendo que os tipos de moldagem estão ligados à plasticidade e à quantidade de água adicionada.

Existem quatro processos básicos de moldagem, são eles:

a) Moldagem a seco ou semisseco (com 4 a $10 \%$ de água): é feita por prensagem. Nesse tipo de moldagem, a argila é moldada quase seca, mas então, para adquirir a forma desejada, ela deve passar por prensas específicas, tais como, a prensa mecânica, hidráulica ou a isostática segundo o Guia Técnico Ambiental da Indústria de Cerâmica Branca e de Revestimento. Essa moldagem é usada para produzir ladrilhos, azulejos, refratários, isoladores elétricos e para tijolos e telhas de superior qualidade (AMBROZEWICZ, 2012); 
b) Moldagem com pasta plástica consistente (com 20 a 35\% de água): é usada a extrusão, onde por meio de uma maromba é possível dar forma e reduzir ao máximo o ar (utilizando-se de uma câmara de vácuo para diminuir a porosidade e evitar o fendilhamento no cozimento) que está contido nas massas pela ação das misturas e da água agregada, pelo processo de forçar as massas a passarem, sob pressão, por meio de um bocal apropriado, formando uma fita uniforme e contínua, depois a coluna é cortada no comprimento desejado. A moldagem para esse processo é a usual para tijolos, tijoletas, tubos cerâmicos, telhas e refratários (RIZZATTI ET AL., 2011; BAUER, 2011);

c) Moldagem com pasta mole (com $25 \%$ a $40 \%$ de água): é o processo mais antigo, onde a cerâmica bastante pastosa (devido à quantidade de água que a argila ainda possui) é moldada em moldes de madeira ou no torno de oleiro. É utilizado para a confecção de tijolos brutos, vasos, dentre outros (BAUER, 2011);

d) Moldagem com pasta fluída (com 30 a 50\% de água): nesse tipo de moldagem a cerâmica é dissolvida em água e a solução, vertidas em moldes porosos de gesso. Depois, a água é absorvida e a argila adere às paredes. Quando seca, a peça se retrai e se descola. É o processo usado para porcelanas, louças sanitárias, peças para instalação elétrica e peças de formato complexo (OLIVEIRA; MAGANHA, 2006).

Dois tipos de argilas foram submetidas a três técnicas: prensagem, extrusão e moldagem, em seguidas queimadas a duas temperaturas distintas, variando o ciclo de aquecimento (rápido e lento), foi apresentado que a resistência mecânica, distribuição de tamanho e diâmetro dos poros não refletem claramente a influência de moldar técnicas, utilizando cerâmica não calcárias (CARRETERO ET AL., 2002).

\subsection{SECAGEM}

Esse é um processo tão importante quanto o cozimento, pois na cerâmica ainda restam cerca de $5 \%$ a $35 \%$ de água. Os processos de secagem se caracterizam como sendo de cunho natural ou artificial, podendo ele ser classificado como contínuo ou intermitente, a depender do tipo de forno utilizado, do mais rudimentar aos mais moderno e tecnológico (AMBROZEWICZ, 2012; BAUER, 2011).

Os quatros processos básicos de secagem são:

a) Secagem natural: é o processo comum nas olarias, mas é demorado e exige grandes superfícies para que se possam colocar os produtos. Ela é feita em telheiros extensos, ao abrigo do sol e com ventilação controlada (BAUER, 2011);

b) Secagem por ar quente-úmido: o material é posto nos secadores, onde recebe ar quente com alto teor de umidade, até que desapareça a água absorvida. Aí então recebe só ar quente, para perder a água de capilaridade (OLIVEIRA ET AL., 2007), a capilaridade se refere ao escoamento de um líquido por meio dos poros. Com isso as deformações são mínimas;

c) Secadores de túnel: são túneis de alguma extensão, pelos quais se faz passar o calor residual dos fornos (de $40^{\circ} \mathrm{C}$ a $150^{\circ} \mathrm{C}$ ). As peças são colocadas em vagonetas, que percorrem lentamente o túnel no sentido da menor para a maior temperatura para assim evitar patologias precoces e perda de material (BAUER, 2011);

d) Secagem por irradiação infravermelha: é pouco usada, em razão do custo e por só servir para peças delgadas, de acordo com Menezes (2007) a cerâmica geralmente é transparente às micro-ondas, porém, quando aquecidas acima de uma temperatura determinada (temperatura crítica), passam a absorver mais eficientemente a radiação de micro- 
-ondas. No entanto, dá alto rendimento e pouca deformação. É usada para peças de precisão.

\subsection{QUEIMA [COZIMENTO)}

É talvez o processo mais importante para a fabricação de materiais cerâmicos, pois toda a água é eliminada nessa fase, ocorrendo mudanças químicas e estruturais na argila. Por isso, a marcha de aquecimento e resfriamento precisa ser controlada (de uma temperatura menor para uma maior, para evitar trincamento e/ou deformidade do material) e diferenciada para cada tipo de peça. De acordo com Ambrozewicz (2012), existem basicamente três fases de queima:

a) Desidratação $\left(150{ }^{\circ} \mathrm{C}\right.$ a $\left.600{ }^{\circ} \mathrm{C}\right)$ : complementa a secagem, onde se perde a água de capilaridade (água que se encontra entre as fendas do material);

b) Oxidação $\left(600^{\circ} \mathrm{C}\right.$ a $\left.950^{\circ} \mathrm{C}\right)$ : queima a matéria orgânica e elimina o carvão e o enxofre, para evitar possíveis patologias e melhorar a qualidade do produto;

c) Vitrificação $\left(950^{\circ} \mathrm{C}\right.$ a $\left.1200^{\circ} \mathrm{C}\right)$ : a sílica (areia) se funde, formando pequenas quantidades de vidro, que aglutinam os demais elementos e fecham os poros dando resistência ao material, essa é a fase onde ocorrem mudanças químicas.

\section{CONCLUSÃO}

Diante da análise dos processos é possível perceber a importância de cada etapa (exploração, extração, tratamento, moldagem, cozimento e secagem), pois cada uma delas pode influenciar nas características dos materiais produzidos de maneira particular, caso sejam realizadas de forma despreocupada.

O intuito deste trabalho foi reunir, de um modo geral, informações sobre as etapas básicas que todos os tipos de materiais cerâmicos necessitam passar para assim se formar, bem como determinar a potencialidade de uma região, quanto à possibilidade de existirem ocorrências favoráveis ou não para a exploração de jazidas.

\section{REFERÊNCIAS}

AMBROZEWICZ, P.H.L. Materiais de construção. São Paulo: PINI, 2012.

ASSOCIAÇÃO Nacional da Indústria Cerâmica ANICER, 2014. Dados Oficiais. Rio de Janeiro.

BAUER, L.A. FALCÃO. Materiais de construção. 5.ed., v.2. Rio de Janeiro: LTC, 2011.

BRITO, I.P. et al. Avaliação de novos depósitos de argilas do Estado da Paraíba visando sua aplicação como matérias-primas cerâmicas. Cerâmica, v.61, n.360, São Paulo , dez. 2015 . p.391-398.

CARRETERO, M.I.; DONDI, M.; FABBRI, B.; RAIMONDO $M$. The influence of shaping and firing technology on ceramic properties of calcareous and non-calcareous illitic-chloritic clays. Applied Clay Science, Issue 6, 2002. p.301-306. ISSN 0169-1317.

COELHO, A.C. VIEIRA; SANTOS, P.S.; SANTOS, H. DE S. Argilas especiais: o que são, caracterização e propriedades. Quím. Nova, v.30, n.1, São Paulo , 2007. p.146-152.

GEONORTE. Edição Especial, v.3, n.4, 2012. p.1503-1514.

MECHI, A., SANCHES, D.L. Impactos ambientais da mineração no Estado de São Paulo. Estud. av. [online], v.24, n.68, 2010. p.209-220. ISSN 0103-4014.

MENEZES, R.R.; SOUTO, P.M.; KIMINAMI, R.H.G.A.. Sinterização de cerâmicas em micro-ondas. Parte l: aspectos fundamentais. Cerâmica, v.53, n.325, São Paulo, 2007. p.1-10. 
MINEROPAR. A preparação de argilas para a produção de telhas e blocos cerâmicos. Curitiba, 2007. p.36.

OLIVEIRA, I.R.; SALOMAO, R.; PANDOLFELLI, V.C. Aditivos e sua influência no comportamento de secagem e resistência à tração de concretos refratários. Cerâmica [on-line], v.53, n.328, 2007. p.396-403.

OLIVEIRA, M.C.E.; MAGANHA, M.F.B. Guia técnico ambiental da indústria de cerâmicas branca e de revestimentos, São Paulo: CETESB, 2006.

OLIVEIRA, T.Y.M. Estudo sobre o uso de materiais de construção alternativos que otimizam a sustentabilidade em edificações. 2015. Monografia (Curso de Engenharia Civil) - Escola Politécnica, Universidade Federal do Rio de Janeiro, Rio de Janeiro, 2015.
PASCHOAL L.G.; CUNHA, C.M.L. Cartografia geomorfológica e as transformações morfohidrográficas em áreas de atividade de mineração de argila: o caso do afluente do Ribeirão Santa Gertrudes/Sp. 2010. Mestrado (Geologia Regional) - Universidade Estadual Paulista Júlio de Mesquita Filho, Rio Claro-SP, 2010.

SILVA, L.D.; SILVA, W.P.; SILVA, C.M.D.P.S.; FARIAS, V.S.O. Descrição da secagem de placas cerâmicas por meio de um modelo de difusão. Cerâmica [on-line], v.59, n.351, 2013. p.409-416.

SILVA, M.R. Materiais de construção. 2.ed. São Paulo: Pini, 1991.

UMMARTYOTIN, S.; BUNNAK, N.; MANUSPIYA, $\mathrm{H}$. A comprehensive review on modified clay based composite for energy based materials. Renewable and Sustainable Energy Reviews, v.61, 2016. p.466-472. 